\title{
Clotting functional stability of withdrawing blood in storage for acute normovolemic hemodilution: a pilot study
}

\author{
Hirotaka Kinoshita ${ }^{1}$ Junichi Saito ${ }^{1}$ (1) $\cdot$ Kishiko Nakai $^{1} \cdot$ Satoko Noguchi $^{1} \cdot$ Daiki Takekawa $^{1} \cdot$ Yoshiko Tamai $^{2}$. \\ Masato Kitayama ${ }^{3} \cdot K^{\prime}$ azuyoshi Hirota ${ }^{1}$
}

Received: 31 March 2020 / Accepted: 12 September 2020 / Published online: 25 September 2020

(c) The Author(s) 2020

\begin{abstract}
Purpose This study was conducted to time-course changes of clotting function of withdrawing blood for acute normovolemic hemodilution (ANH).

Methods Twelve enrolled patients who underwent ANH from August, 2018 to January, 2019. Blood was withdrawn into blood collection pack and shaken at $60-80 \mathrm{rpm}$ for $24 \mathrm{~h}$ in room temperature. Clot formation was evaluated using rotational thromboelastometry (ROTEM ${ }^{\mathrm{TM}}$ ) just after blood withdrawal (control) and 4, 8, 12 and $24 \mathrm{~h}$ after blood withdrawal. We compared with the control value and each value of extrinsically-activated test with tissue factor (EXTEM), intrinsicallyactivated test using ellagic acid (INTEM) and fibrin-based extrinsically activated test with tissue factor (FIBTEM).

Results Maximum clot firmness (MCF) of FIBTEM did not change significantly. MCF of EXTEM was significantly decreased time-dependent manner but all MCF of EXTEM were within a normal range. Maximum percent change in MCF of EXTEM was $12.4 \%$ [95\% confidence interval (CI): 9.0-15.8\%]. The difference in the maximum clot elasticity (MCE) between EXTEM and FIBTEM (MCE $\left.\mathrm{EXTEM}-\mathrm{MCE}_{\mathrm{FIBTEM}}\right)$ was significantly decrease from $8 \mathrm{~h}$ after blood withdrawal. Maximum percent change in $\mathrm{MCE}_{\mathrm{EXTEM}}-\mathrm{MCE}_{\mathrm{FIBTEM}}$ was $30.2 \%$ (95\% CI:17.6-42.9\%) at $24 \mathrm{~h}$ after blood withdrawal. Conclusion Even though the MCE significantly decreased in a time-dependent manner, MCF of FIBTEM and EXTEM was normal up to $24 \mathrm{~h}$ storage. The blood of ANH can use for the purpose of hemostasis at least $8 \mathrm{~h}$ stored at room temperature after blood withdrawal. Future studies are needed to elucidate the clinical impact on the patient after delayed transfusion of ANH blood with regard to patient's hemostasis.
\end{abstract}

Keywords Clotting function - Acute normovolemic hemodilution · Thromboelastometry · Autologous transfusion

Electronic supplementary material The online version of this article (https://doi.org/10.1007/s00540-020-02856-x) contains supplementary material, which is available to authorized users.

Junichi Saito

saitoj@hirosaki-u.ac.jp

Hirotaka Kinoshita

hirotaka091028@gmail.com

Kishiko Nakai

kishiko_sk1064@yahoo.co.jp

Satoko Noguchi

satko1110@yahoo.co.jp

Daiki Takekawa

takekawa.daiki50@gmail.com

Yoshiko Tamai

ytamai@hirosaki-u.ac.jp
Masato Kitayama

kitasan@hirosaki-u.ac.jp

Kazuyoshi Hirota

hirotak@hirosaki-u.ac.jp

1 Department of Anesthesiology, Hirosaki University Graduate School of Medicine, Zaifu-cho 5, Hirosaki 036-8562, Japan

2 Department of Transfusion and Cell Therapy Medicine, Hirosaki University Graduate School of Medicine, Hirosaki, Japan

3 Division of Operating Center, Hirosaki University Medical Hospital, Hirosaki, Japan 


\section{Introduction}

Acute normovolemic hemodilution (ANH) is usually carried out to preserve red blood cell, leading reduce the amount of intra- and postoperative allogenic blood transfusion in several clinical settings [1-5]. Moreover, in cardiovascular surgical setting, in addition to the reduction of the risk of postoperative allogeneic blood transfusion, ANH also can reduce the amount of post-operative blood loss [6]. Since ANH blood has not been exposed to the cardiopulmonary bypass (CPB), coagulation factors including fibrinogen and platelet function should be preserved and contribute to hemostasis after surgery.

ANH blood is usually stored at ambient temperature to maintain platelet function during surgery. Storing whole blood at ambient temperature for $24 \mathrm{~h}$ has minimal effect on the coagulation activity of plasma, except factor VIII (fVIII) which was loss of 20-30\% during first $8 \mathrm{~h}[7,8]$. However, time dependent changes of clotting function of whole blood has not well determined. We hypothesized that coagulation activity of ANH storing at room temperature would be maintained throughout $24 \mathrm{~h}$. To evaluate our hypothesis, we conducted this study to determine the time dependent changes of the clotting function of the ANH withdrawing blood in storage.

\section{Methods}

The protocol of this prospective observational study was approved by the local Ethics committee, publicized on our hospital homepage (2018-1040) and was registered prior to patient enrollment in a publicly accessible database, the UMIN clinical trial registry, which is one registry of the Japan primary registries network (UMIN000033017, Principal investigator: Junichi SAITO, Date of registration: 15 Jun, 2018). Written informed consent from each patient was waived because blood samples in the tube of blood packs were usually thrown away and the Ethic committee approved the waiver. We enrolled 12 patients who was scheduled to conduct $800 \mathrm{~mL}$ of ANH before surgery at Hirosaki University Hospital from August 1, 2018 to January 31, 2019. The primary outcome was the time dependent changes of clotting function of ANH until $24 \mathrm{~h}$ after withdrawal of ANH.

\section{ANH procedure and collected blood sample}

The principle indication of ANH in our hospital is an estimated blood loss more than $500 \mathrm{~mL}$ or request by surgeons for patients to have more than $10 \mathrm{~g} / \mathrm{dL}$ of hemoglobin $(\mathrm{Hb})$ after surgery. The amount of blood withdrawal for ANH was
$800 \mathrm{~mL}$ in all cases, about $20 \%$ of blood volume. Autologous whole blood of $400 \mathrm{~mL}$ was collected using a decompression blood collecting equipment (Hemo-Quic; AC-181 TERUMO, Tokyo, Japan). After induction of anesthesia in the operating room, blood was withdrawn twice from the central venous line into each standard blood collection pack (JMS Blood Bag CPD400; JMS, Tokyo, Japan) containing citrate phosphate dextrose solution with hemodilution with $500-1000 \mathrm{~mL}$ of $6 \%$ hydroxyethyl starch (130/0.4) (Voluvein; Fresenius Kabi, Bad Homburg, Germany) to maintain the patient's normovolemia and mean artery pressure $\geq 60 \mathrm{mmHg}$. ANH procedure took 20-25 min to collect $800 \mathrm{~mL}$ of blood. After collection of blood into the blood pack, tube was sealed by tube sealer. Blood in the tube put in the test tube containing citrate phosphate dextrose solution $1.5 \mathrm{~mL}$ which was same solution of the standard blood collection packs. As the company supplies the sodium citrate contained tube for measuring rotational thromboelastometry (ROTEM $^{\mathrm{TM}}$ : Pentapharm GmbH, Munich, Germany), the impact of storage solution on ROTEM ${ }^{\mathrm{TM}}$ measurement is considered to be limited. The amount of blood in the tube of each blood pack was $5 \mathrm{~mL}$. About $10 \mathrm{~mL}$ of blood sample (mixing the blood of both blood packs) was collected from each patient. ROTEM has some advantages to evaluate the entire clotting function using smaller amount of blood compared with conventional clotting functional test and, thus, ROTEM was suitable to measure clotting function repeatedly in this study. Blood sample in the test tube were shaken 60-80 rpm during $24 \mathrm{~h}$ in the room temperature. When a specimen was removed, collected autologous blood was reinfused to the patient.

\section{Data collection and global tests of hemostasis}

Patient's demographics, pre-operative platelet counts, prothrombin time and activated partial thromboplastin time were collected. Intraoperative laboratory data, including hemoglobin, hematocrit and platelet counts after withdrawal blood and after re-infusion ANH blood to the patients were also collected. Clot formation was evaluated by ROTEM ${ }^{\mathrm{TM}}$ (Fig. 1) and the measurements were at just after withdrawal of blood (within $1 \mathrm{~h}$ ) and 4, 8, 12 and $24 \mathrm{~h}$ after withdrawal. To ensure the accuracy of the ROTEM ${ }^{\mathrm{TM}}$ measurement, designated two physicians measured ROTEM ${ }^{\mathrm{TM}}$ with the same ROTEM ${ }^{\mathrm{TM}}$ machine. The measurements were clotting time (CT), clot formation time (CFT), and maximum clot firmness (MCF) of extrinsically-activated test with tissue factor (EXTEM), intrinsically-activated test using ellagic acid (INTEM) and fibrin-based extrinsically activated test with tissue factor and the platelet inhibitor cytochalasin D (FIBTEM). The platelets contribution to clot elasticity (platelet component parameter) can be calculated from the difference in the maximum clot elasticity 


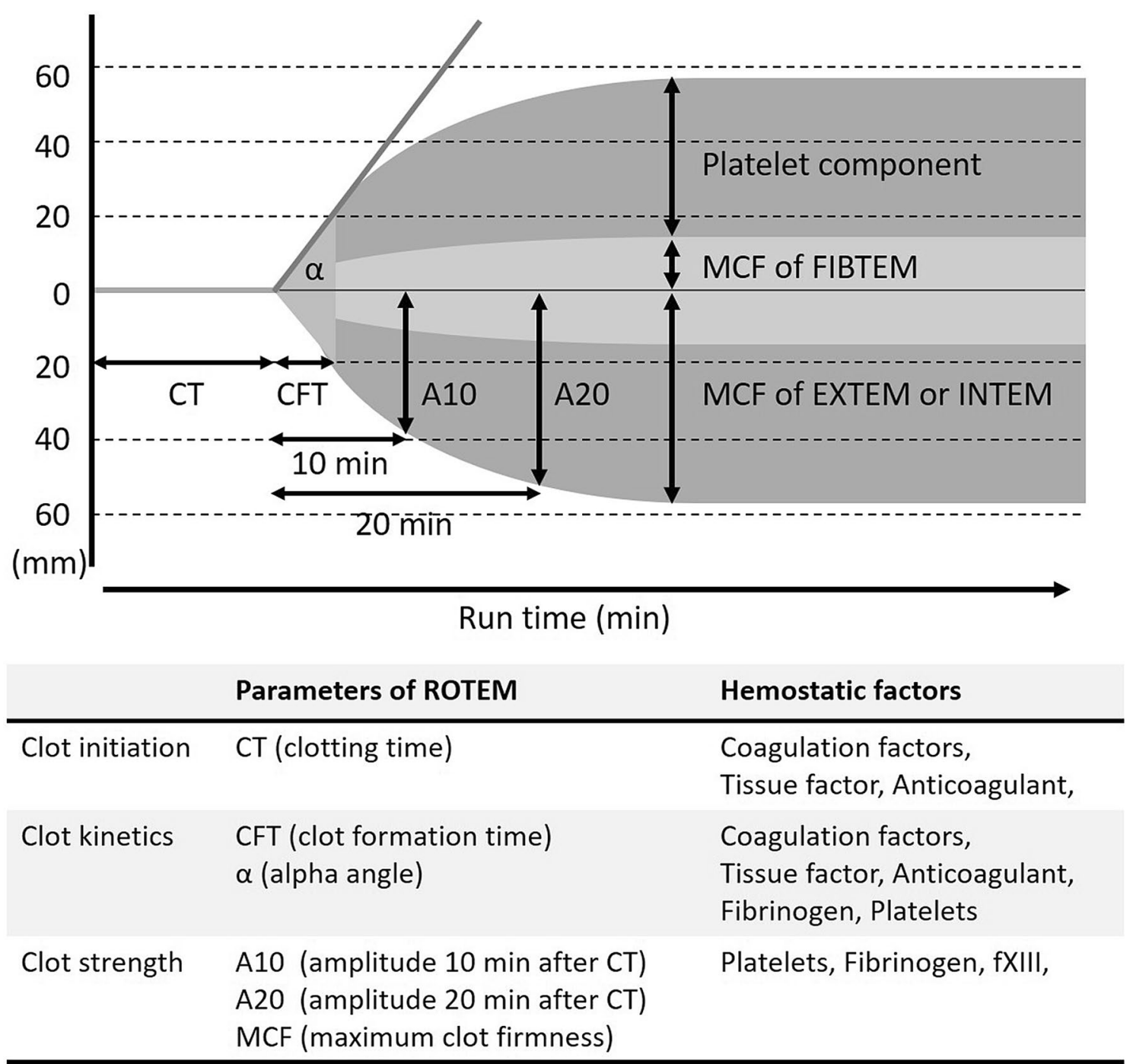

Fig. 1 Main parameters of ROTEMTM. EXTEM extrinsically-activated test with tissue factor, INTEM intrinsically-activated test using ellagic acid, FIBTEM fibrin-based extrinsically activated test with tissue factor and the platelet inhibitor cytochalasin D

(MCE) between EXTEM and FIBTEM ( $\mathrm{MCE}_{\text {EXTEM }}-\mathrm{MCE}$ FIBTEM). MCE was calculated using the following formula: $\mathrm{MCE}=(\mathrm{MCF} \times 100) /(100-\mathrm{MCF})[9]$.

\section{Statistical analyses}

The statistical analyses were performed using GraphPad Prism V7 (GraphPad Software, La Jolla, CA). Repeatedmeasures analysis of variance (ANOVA) with Bonferroni post hoc corrections was used to compare with the control value and each value of EXTEM, INTEM and FIBTEM. The sample size was calculated using with $\mathrm{G} \times$ Power 3.1.9.2 (Universität Düsseldorf, Düsseldorf, Germany). When running a power analysis on a repeated-measures ANOVA with 5 measurements, a power of 0.8 , an alpha level of 0.0125 , correlation among repeated measures of 0.66 , nonsphericity correction of 0.25 , and a medium effect size $(f=0.25)$ [10], the required sample size is at least 52. The authors included 12 patients with 60 sample readings. All data are presented as mean \pm the standard error of the mean (SEM) or median (25th to 75 th percentile). All statistical tests were twosided, and a $p$ value of $<0.05$ was considered statistically significant.

\section{Results}

Demographic and preoperative laboratory data were presented in the Table 1 . The baseline values of each variable of ROTEM ${ }^{\mathrm{TM}}$ were within the normal range. CT of EXTEM (Table 2), INTEM (supplemental Table 1) and FIBTEM (Table 3) did not change significantly during the 
Table 1 Characteristics of 12 patients and peri-operative laboratory data

\begin{tabular}{|c|c|c|c|}
\hline \multicolumn{4}{|l|}{ Characteristics of patients } \\
\hline Male, $n(\%)$ & & & $6(50)$ \\
\hline Age, years & & & $64(56,70)$ \\
\hline Height, $\mathrm{cm}$ & & & $157(155,160)$ \\
\hline Body weight, $\mathrm{kg}$ & & & $57 \pm 16$ \\
\hline \multicolumn{4}{|l|}{ Intra-operative data } \\
\hline Blood loss, $\mathrm{g}$ & & & $604 \pm 748$ \\
\hline Urine out, $\mathrm{mL}$ & & & $1326 \pm 1454$ \\
\hline Crystalloid solution, $\mathrm{mL}$ & & & $2735 \pm 1655$ \\
\hline Colloid solution, $\mathrm{mL}$ & & & $816 \pm 489$ \\
\hline $\mathrm{RBC}, n(\%)$ & & & $2(17)$ \\
\hline FFP, $n(\%)$ & & & $2(17)$ \\
\hline $\mathrm{PC}, n(\%)$ & & & $1(8)$ \\
\hline Laboratory data & Pre-ANH & After withdrawal & After re-transfusion \\
\hline $\mathrm{Hb}, \mathrm{g} / \mathrm{dL}$ & $13.9 \pm 1.4$ & $9.5 \pm 1.6$ & $9.5 \pm 1.8$ \\
\hline Ht. \% & $40.9 \pm 3.6$ & $27.6 \pm 4.2$ & $27.6 \pm 5.1$ \\
\hline $\mathrm{Plt} \times 10^{4} / \mu \mathrm{L}$ & $22.9 \pm 5.1$ & $15.8 \pm 5.2$ & $14.7 \pm 4.4$ \\
\hline PT, s & $11.5 \pm 0.8$ & & \\
\hline PT-INR & $0.99 \pm 0.08$ & & \\
\hline APTT, s & $28.5(27.9,31.9)$ & & \\
\hline Fibrinogen, mg/dL & $274(252,294)$ & & \\
\hline
\end{tabular}

Mean $\pm \mathrm{SD}$, Median (25th, 75th percentile), $n(\%)$ : the number and proportion of patients

$A N H$ acute normovolemic hemodilution, $R B C$ red blood cells, $F F P$ fresh frozen plasma, $P C$ platelets concentrate, $H b$ hemoglobin, $H t$ hematocrit, $P l t$ platelet count, $P T$ prothrombin time, INR international normalized ratio, APTT activated partial thromboplastin time

Table 2 Changes in each variable in EXTEM

\begin{tabular}{llrcccc}
\hline EXTEM & Reference range [11] & 0 & $4 \mathrm{~h}$ & $8 \mathrm{~h}$ & $12 \mathrm{~h}$ & $24 \mathrm{~h}$ \\
\hline $\mathrm{CT}, \mathrm{s}$ & $42-74$ & $67 \pm 6$ & $55 \pm 5$ & $61 \pm 7$ & $60 \pm 3$ & $64 \pm 6$ \\
$\mathrm{CFT}, \mathrm{s}$ & $46-148$ & $111 \pm 5$ & $121 \pm 11$ & $133 \pm 9$ & $120 \pm 9$ & $141 \pm 7^{* *}$ \\
$\mathrm{MCF}, \mathrm{mm}$ & $49-71$ & $62 \pm 1$ & $61 \pm 1$ & $58 \pm 1^{* * *}$ & $56 \pm 2^{*}$ & $55 \pm 1^{* * *}$ \\
$\mathrm{MCE}$, & $105-235$ & $167 \pm 6$ & $155 \pm 4$ & $139 \pm 6^{* * *}$ & $131 \pm 10^{*}$ & $121 \pm 5^{* * *}$ \\
$\left(\mathrm{G} \mathrm{dynes} / \mathrm{cm}^{2}\right) / 50$ & & & & & & \\
\hline
\end{tabular}

Mean \pm SEM

$C T$ clotting time $C F T$ clot formation time, $M C F$ maximum clot firmness, $M C E$ maximal clot elasticity; $* p<0.05, * * p<0.01, * * * p<0.001$ vs. 0

Table 3 Changes in each variable in FIBTEM

\begin{tabular}{lllllll}
\hline FIBTEM & $\begin{array}{l}\text { Reference } \\
\text { range [11] }\end{array}$ & 0 & $4 \mathrm{~h}$ & $8 \mathrm{~h}$ & $12 \mathrm{~h}$ & $24 \mathrm{~h}$ \\
\hline $\mathrm{CT}, \mathrm{s}$ & $43-69$ & $59 \pm 3$ & $56 \pm 5$ & $61 \pm 4$ & $47 \pm 4$ & $52 \pm 3$ \\
$\mathrm{MCF}, \mathrm{mm}$ & $9-25$ & $15 \pm 2$ & $15 \pm 2$ & $13 \pm 1$ & $14 \pm 1$ & $14 \pm 1$ \\
$\mathrm{MCE}$, & $13-27$ & $18 \pm 2$ & $19 \pm 4$ & $15 \pm 2$ & $17 \pm 2$ & $16 \pm 1$ \\
$\left(\mathrm{G} \mathrm{dynes} / \mathrm{cm}^{2}\right) / 50$ & & & & & & \\
\hline
\end{tabular}

Mean \pm SEM

$C T$ clotting time, $C F T$ clot formation time, $M C F$ maximum clot firmness, $M C E$ maximal clot elasticity 
study period. CFT of EXTEM and INTEM was increased in a time-dependent manner but that of EXTEM $24 \mathrm{~h}$ after blood withdrawal and INTEM $12 \mathrm{~h}$ after blood withdrawal was significantly increased. MCF of FIBTEM did not change significantly but that of EXTEM and INTEM were decreased in a time-dependent manner. That of EXTEM were significantly decreased from $8 \mathrm{~h}$ after withdrawing blood but all MCF of EXTEM were within normal physiological ranges. That of INTEM were significantly decreased from $4 \mathrm{~h}$ after blood withdrawal and only one reading $(49 \mathrm{~mm}$ of MCF of INTEM) was below the normal limit (52-72 $\mathrm{mm}$ of MCF INTEM) [11]. Maximum percent changes in MCF of EXTEM and INTEM were $12.4 \%$ [95\% confidence interval (CI): 9.0-15.8\%] and 11.6\% (95\% CI: 6.8-16.4\%), respectively (Fig. 2a and Supplemental Fig. 1). MCE of
EXTEM and INTEM were significantly decreased timedependent manner but that of FIBTEM did not changed. $\mathrm{MCE}_{\text {EXTEM }}-\mathrm{MCE}_{\mathrm{FIBTEM}}$ was significantly decrease from $8 \mathrm{~h}$ after blood withdrawal. Maximum percent change in $\mathrm{MCE}_{\text {EXTEM }}-\mathrm{MCE}_{\text {FIBTEM }}$ was $30.2 \%$ [95\% CI: 17.6-42.9\%] at $24 \mathrm{~h}$ after blood withdrawal (Fig. 2b).

\section{Discussion}

This prospective observational study revealed clinical important issues. Even though platelet component parameter $\left(\mathrm{MCE}_{\mathrm{EXTEM}}-\mathrm{MCE}_{\mathrm{FIBTEM}}\right)$ was significantly decreased in a time-dependent manner from $8 \mathrm{~h}$ after blood withdrawal, MCF of FIBTEM remained unchanged and that of
Fig. 2 Fraction changes in maximum clot firmness and maximal clot elasticity. a Fraction changes in maximum clot firmness of extrinsicallyactivated test with tissue factor (EXTEM). b Fraction changes in the difference in maximal clot elasticity (MCE) between EXTEM and FIBTEM $\left(\mathrm{MCE}_{\mathrm{EXTEM}}-\mathrm{MCE}_{\mathrm{FIBTEM}}\right)$; Mean \pm SEM, $* p<0.05$, $* * p<0.01,{ }^{*} p<0.001$ vs. 0

\section{A}

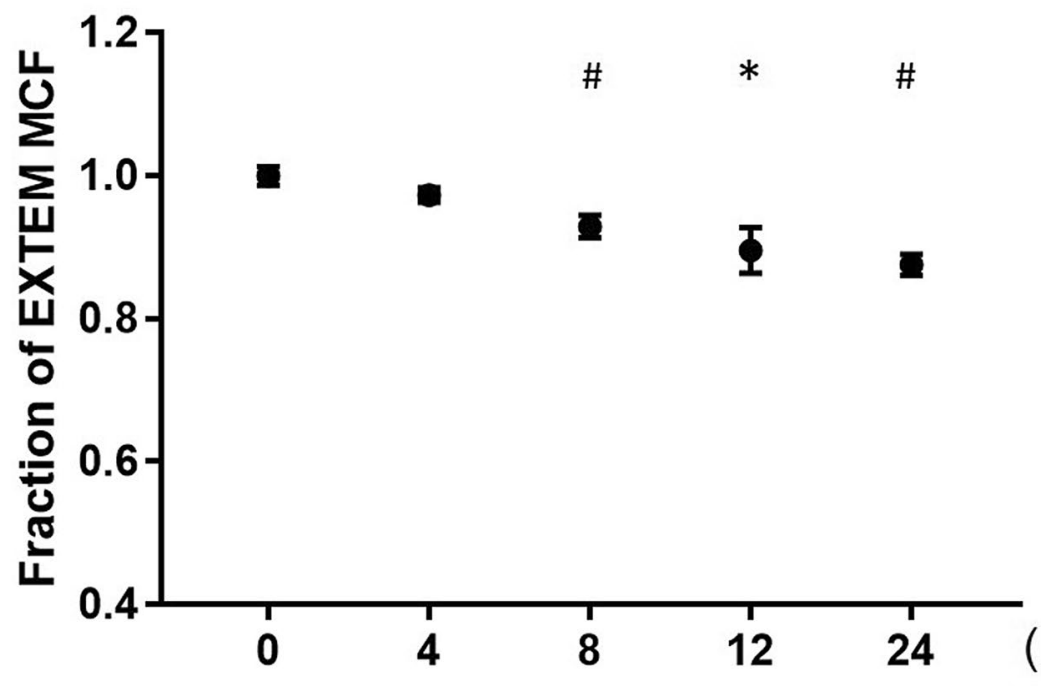

(h)

\section{B}

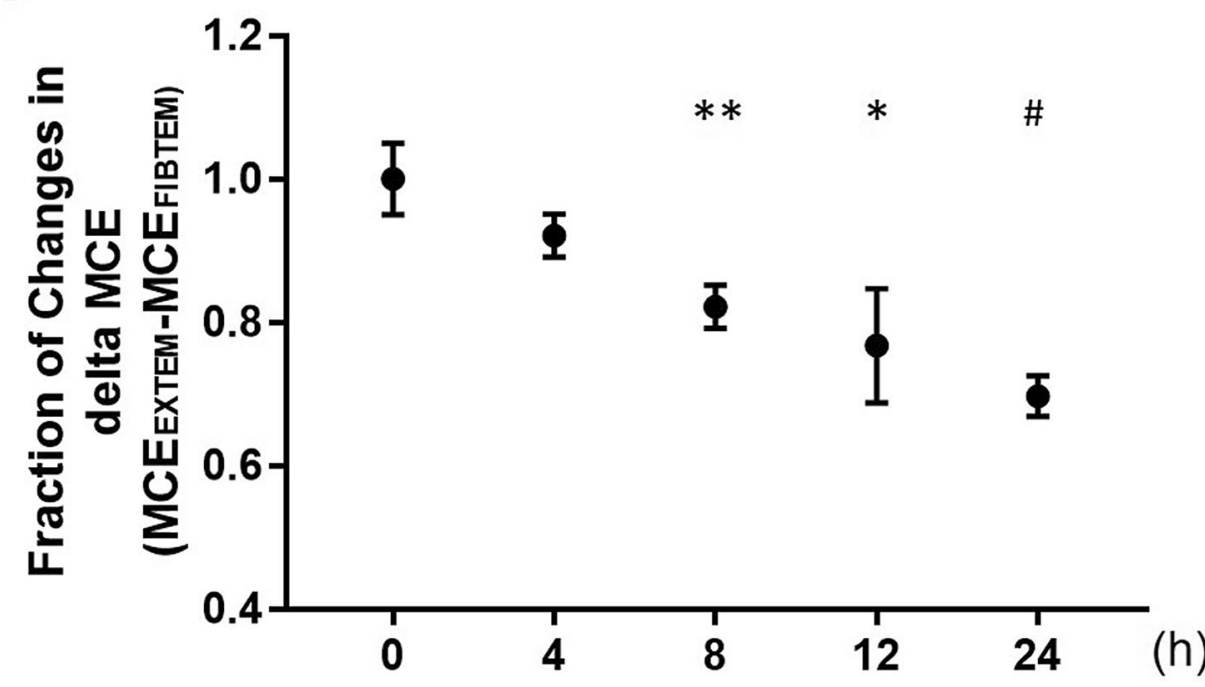


EXTEM and INTEM was within reference ranges after $24 \mathrm{~h}$ after blood withdrawal. This result suggests that the blood of ANH can use for the purpose of hemostasis at least $8 \mathrm{~h}$ stored at the room temperature after blood withdrawal.

Stability of MCF of FIBTEM in this study is supported by the fact that plasma fibrinogen concentration remains unchanged after $24 \mathrm{~h}$ after blood collection [7, 8, 12]. In addition, a prospective observational study investigated the coagulation profiles of cold-stored autologous whole blood in using ROTEM ${ }^{\mathrm{TM}}$ and revealed that CT of EXTEM and INTEM increased with increasing cold storage duration (7-33 days) but fibrinogen level was not affected by the storage duration. These results indicated that cold-stored autologous whole blood retains fibrin polymerization properties throughout 33 days even though extrinsic and intrinsic coagulation factors decreased in a time-dependent manner [13]. MCF of FIBTEM and plasma fibrinogen concentration have strong correlation in pediatric and adult surgical patients $[14,15]$. The unchanged MCF of FIBTEM is estimated to have no change in the plasma fibrinogen concentration in the blood of ANH.

Platelet component parameter $\left(\mathrm{MCE}_{\mathrm{EXTEM}}-\mathrm{MCE}_{\mathrm{FIBTEM}}\right)$ was significantly decreased in a time-dependent manner from $8 \mathrm{~h}$ after blood withdrawal. Maximum percent change in $\mathrm{MCE}_{\text {EXTEM }}-\mathrm{MCE}_{\text {FIBTEM }}$ was about $30 \%$ at $24 \mathrm{~h}$ after blood withdrawal. Even if the whole blood was stored at room temperature and no apparent clot formation in the tube, the platelet function or platelet count could decrease in a time-dependent manner. Transfusion of ANH blood to the patients as soon as possible may be suitable from the perspective of maintaining platelet function or platelet count.

Platelets are recommended to store at room temperature with agitation because refrigeration $\left(2-6{ }^{\circ} \mathrm{C}\right)$ led to rapid clearance from the circulation upon transfusion ( $\mathrm{t} 1 / 2=1-2$ days), which was significantly reduced compared to room temperature storage $\left(22-24^{\circ} \mathrm{C}\right)(\mathrm{t} 1 / 2=7-9$ days $)$ [16]. However, there is growing evidence that cold storage of platelets is superior to room temperature storage of platelets [17]. Platelet rich plasma storing at cold temperature enhances platelet activation and aggregation, and cold storage of platelets in whole blood improves their performance in a panel of functional assays compared to platelets storing at room temperature $[18,19]$. Storage temperature of platelets and whole blood is still controversial, and warrant further studies regarding the impact of storage temperature on ANH coagulation.

To our knowledge, the changes in the activity of coagulation factors and platelets on clotting function of whole blood were not well evaluated. However, our present findings support the report that the storage of whole blood at room temperature could change the clotting function of whole blood within several hours [20]. A recent clinical study showed that CFT, $\alpha$-angle and MCF of EXTEM and
FIBTEM significantly changed between withdrawing and reinfusion of the ANH blood after an average of almost $5 \mathrm{~h}$ in storage in patients undergoing cardiac surgery [20]. They also showed the decrease in platelets aggregation induced by thrombin receptor activating peptide 6 stimulation during storage, even though the magnitude of change was not significantly correlated with time of storage [20]. These results suggest that platelet function affects the clotting function of $\mathrm{ANH}$ and the ROTEM ${ }^{\mathrm{TM}}$ measurements.

CFT and MCF of EXTEM and INTEM of the blood of ANH were significantly changed in a time-dependent manner. Activity of fVIII rapidly decreases $20-30 \%$ during first $8 \mathrm{~h}$ of storage [7, 8]. One retrospective study showed that fVIII was strongly correlated $(r \leq-0.8$ or $\geq 0.8)$ with MCF and CFT of EXTEM and INTEM and MCF of FIBTEM in major surgical patients with hemorrhage [21]. This result suggests that not only platelets, fibrinogen and fXIII [22] but also fVIII had a significant impact on ROTEM ${ }^{\mathrm{TM}}$ measurements.

Changes in activity of each coagulation factor during storage at room temperature have been well evaluated in the previous studies $[7,8,12]$. In addition to activity of fVIII, activities of fII, fIX, $\mathrm{fX}$, protein $\mathrm{C}$ and protein $\mathrm{S}$ were significantly decreased $24 \mathrm{~h}$ after blood collection [8]. Even though the activity of all coagulation factors in plasma produced from whole blood stored for $24 \mathrm{~h}$ remained above $0.50 \mathrm{U} /$ $\mathrm{mL}$ [8], the present results suggested that decreased activity of these factors has an impact on ROTEM ${ }^{\mathrm{TM}}$ measurements. Changes in CFT and MCF might reflect of decreased activity of coagulation factors, especially fVIII, in our study.

This study has some limitations. First, the ROTEM ${ }^{\mathrm{TM}}$ measurement was once at each measurement point. A coefficient of variation (CV) of ROTEM ${ }^{\mathrm{TM}}$ is small; the average \pm SD of the CV between-dupilcates vas $4.3 \% \pm 3.8 \%$ of CFT and $1.2 \% \pm 1.1 \%$ of MCF, respectively [23]. Thus, the impact of ROTEM ${ }^{\mathrm{TM}}$ measurement on the result is likely not significant. Second, standard platelet function test and platelet count were not measured in this study. Even though previous studies revealed that the donated blood stored overnight (18-26 h) has little impact on these laboratory examination [24-26], it is well known that many factors could affect platelet function and quality during storage [27], especially oxygen partial pressure, $\mathrm{pH}$ and glucose level are affected by the storage duration [26], we should pay more attention to maintain the storage condition. Further studies for the future are needed to elucidate the clinical impact on the patient after delayed transfusion of ANH blood with regard to hemostasis. Third, we did not evaluate the bacterial contamination during storage. Longer duration of storage might increase the risk of bacterial infection. But almost all surgical patients are received anti-bacterial drugs just after induction of anesthesia. The risk of bacterial contamination seems less compared with normal blood donation. 
Nevertheless, we should pay attention to maintain sterilized condition during ANH procedure and storage.

In conclusion, even though platelet component parameter $\left(\mathrm{MCE}_{\mathrm{EXTEM}}-\mathrm{MCE}_{\mathrm{FIBTEM}}\right)$ was significantly decreased timedependent manner from $8 \mathrm{~h}$ after blood withdrawal, MCF of FIBTEM remained unchanged and that of EXTEM was within reference ranges after $24 \mathrm{~h}$ after blood withdrawal. This result suggests that the blood of ANH can use for the purpose of hemostasis at least $8 \mathrm{~h}$ stored at the room temperature after blood withdrawal. Future prospective studies are needed to elucidate the clinical impact on the patient after delayed transfusion of ANH blood with regard to hemostasis.

Acknowledgements The authors thank to Prof Daqing Ma, Imperial College London for his critical comments during manuscript preparation.

Author contributions H.K. design the study, collected data and evaluated the data. J.S. designed the study, collected data, performed the statistical analysis and drafted the manuscript. K.N. designed the study, and evaluated the data. S.N. designed the study and evaluated the data. D.T. designed the study evaluated the data. Y.T. designed the study, evaluated the data and extensively revised the manuscript. M.K. evaluated the data and extensively revised the manuscript. K.H. designed the study, evaluated the data and extensively revised the manuscript. J Saito is the archival author.

Funding This work was supported by JSPS KAKENHI Grant Number JP19K18233.

\section{Compliance with ethical standards}

Conflict of interest All authors declare no conflict of interest. All authors read and approved the final manuscript and attest to the integrity of the original data and the analysis reported in this manuscript.

Ethical approval This study protocol was approved by Hirosaki University's Ethics Committee (2018-1040).

Open Access This article is licensed under a Creative Commons Attribution 4.0 International License, which permits use, sharing, adaptation, distribution and reproduction in any medium or format, as long as you give appropriate credit to the original author(s) and the source, provide a link to the Creative Commons licence, and indicate if changes were made. The images or other third party material in this article are included in the article's Creative Commons licence, unless indicated otherwise in a credit line to the material. If material is not included in the article's Creative Commons licence and your intended use is not permitted by statutory regulation or exceeds the permitted use, you will need to obtain permission directly from the copyright holder. To view a copy of this licence, visit http://creativecommons.org/licenses/by/4.0/.

\section{References}

1. Guo JR, Jin XJ, Yu J, Xu F, Zhang YW, Shen HC, Shao Y. Acute normovolemic hemodilution effects on perioperative coagulation in elderly patients undergoing hepatic carcinectomy. Asian Pac J Cancer Prev. 2013;14:4529-32.

2. Zhou X, Zhang C, Wang Y, Yu L, Yan M. Preoperative acute normovolemic hemodilution for minimizing allogeneic blood transfusion: a meta-analysis. Anesth Analg. 2015;121:1443-555.

3. Tanner EJ, Filippova OT, Gardner GJ, Long Roche KC, Sonoda Y, Zivanovic O, Fischer M, Chi DS. A prospective trial of acute normovolemic hemodilution in patients undergoing primary cytoreductive surgery for advanced ovarian cancer. Gynecol Oncol. 2018;151:433-7.

4. Saito J, Masui K, Noguchi S, Nakai K, Tamai Y, Midorikawa Y, Kinoshita H, Mikami N, Kitayama M, Hashimoto H, Hirota K. The efficacy of acute normovolemic hemodilution for preventing perioperative allogeneic blood transfusion in gynecological cancer patients. J Clin Anesth. 2020;60:42-3.

5. Takekawa D, Saito J, Kinoshita H, Hashiba EI, Hirai N, Yamazaki Y, Kushikata T, Hirota K. Acute normovolemic hemodilution reduced allogeneic blood transfusion without increasing perioperative complications in patients undergoing free-flap reconstruction of the head and neck. J Anesth. 2020;34:187-94.

6. Barile L, Fominskiy E, Di Tomasso N, Alpìzar Castro LE, Landoni G, De Luca M, Bignami E, Sala A, Zangrillo A, Monaco F. Acute normovolemic hemodilution reduces allogeneic red blood cell transfusion in cardiac surgery: a systematic review and metaanalysis of randomized trials. Anesth Analg. 2017;124:743-52.

7. O’Neill EM, Rowley J, Hansson-Wicher M, McCarter S, Ragno G, Valeri CR. Effect of 24-hour whole-blood storage on plasma clotting factors. Transfusion. 1999;39:488-91.

8. Cardigan R, Van der Meer PF, Pergande C, Cookson P, BaumannBaretti B, Cancelas JA, Devine D, Gulliksson H, Vassallo R, de Wildt-Eggen J. Coagulation factor content of plasma produced from whole blood stored for 24 hours at ambient temperature: results from an international multicenter BEST collaborative study. Transfusion. 2011;51(Suppl 1):50-7.

9. Lang T, Johanning K, Metzler H, Piepenbrock S, Solomon C, Rahe-Meyer N, Tanaka KA. The effects of fibrinogen levels on thromboelastometric variables in the presence of thrombocytopenia. Anesth Analg. 2009;108:751-8.

10. Cohen J. The analysis of variance, in Cohen JM: statistical power analysis for the behavioral sciences. 2nd ed. Hillsdale: Lawrence Erlbaum Associates; 1998.

11. Lang T, Bauters A, Braun SL, Pötzsch B, von Pape KW, Kolde HJ, Lakner M. Multi-centre investigation on reference ranges for ROTEM thromboelastometry. Blood Coagul Fibrinolysis. 2005;16:301-10.

12. Thomas S. Ambient overnight hold of whole blood prior to the manufacture of blood components. Transfus Med. 2010;20:361-8.

13. Iwata S, Hirasaki Y, Nomura M, Ozaki M. Thromboelastometric evaluation of coagulation profiles of cold-stored autologous whole blood: a prospective observational study. Medicine (Baltimore). 2019;98:e17357.

14. Mace H, Lightfoot N, McCluskey S, Selby R, Roy D, Timoumi T, Karkouti K. Validity of thromboelastometry for rapid assessment of fibrinogen levels in heparinized samples during cardiac surgery: a retrospective, single-center observational study. J Cardiothorac Vasc Anesth. 2016;30:90-5.

15. Haas T, Spielmann N, Mauch J, Madjdpour C, Speer O, Schmugge $\mathrm{M}$, Weiss M. Comparison of thromboelastometry (ROTEM(R)) with standard plasmatic coagulation testing in paediatric surgery. Br J Anaesth. 2012;108:36-41.

16. Murphy S, Gardner FH. Effect of storage temperature on maintenance of platelet viability-deleterious effect of refrigerated storage. N Engl J Med. 1969;280:1094-8.

17. Reddoch-Cardenas KM, Bynum JA, Meledeo MA, Nair PM, Wu X, Darlington DN, Ramasubramanian AK, Cap AP. Cold-stored 
platelets: a product with function optimized for hemorrhage control. Transfus Apher Sci. 2019;58:16-22.

18. Montgomery RK, Reddoch KM, Evani SJ, Cap AP, Ramasubramanian AK. Enhanced shear-induced platelet aggregation due to low-temperature storage. Transfusion. 2013;53:1520-30.

19. Pidcoke HF, McFaul SJ, Ramasubramanian AK, Parida BK, Mora AG, Fedyk CG, Valdez-Delgado KK, Montgomery RK, Reddoch KM, Rodriguez AC, Aden JK, Jones JA, Bryant RS, Scherer MR, Reddy HL, Goodrich RP, Cap AP. Primary hemostatic capacity of whole blood: a comprehensive analysis of pathogen reduction and refrigeration effects over time. Transfusion. 2013;53(Suppl 1):137S-49S.

20. Scott KJ, Shteamer JW, Szlam F, Sniecinski RM. Platelet function, but not thrombin generation, is impaired in acute normovolemic hemodilution (ANH) blood. J Clin Anesth. 2019;58:39-433.

21. Theusinger OM, Schröder CM, Eismon J, Emmert MY, Seifert B, Spahn DR, Baulig W. The influence of laboratory coagulation tests and clotting factor levels on rotation thromboelastometry (ROTEM(R)) during major surgery with hemorrhage. Anesth Analg. 2013;117:314-21.

22. Theusinger OM, Baulig W, Asmis LM, Seifert B, Spahn DR. In vitro factor XIII supplementation increases clot firmness in rotation thromboelastometry (ROTEM). Thromb Haemost. 2010;104:385-91.

23. Scalambrino E, Padovan L, Clerici M, Chantarangkul V, Biliou S, Peyvandi F, Tripodi A. Thromboelastometry. Reproducibility of duplicate measurement performed by the RoTem(R) device. Thromb Res. 2018;172:139-41.

24. Dijkstra-Tiekstra MJ, van der Meer PF, Cardigan R, Devine D, Prowse C, Sandgren P, de Wildt-Eggen J. Biomedical excellence for safer transfusion collaborative platelet concentrates from fresh or overnight-stored blood, an international study. Transfusion. 2011;51(Suppl 1):38-44S.

25. van der Meer PF, Cancelas JA, Vassallo RR, Rugg N, Einarson M, Hess JR. BEST collaborative. Evaluation of the overnight hold of whole blood at room temperature before component processing: platelets PLTs from PLT-rich plasma. Transfusion. 2011;51(Supp11):45-9.

26. van der Meer PF, de Korte D. The effect of holding times of whole blood and its components during processing on in vitro and in vivo quality. Transfus Med Rev. 2015;29:24-34.

27. Ohto H, Nollet KE. Overview on platelet preservation: better controls over storage lesion. Transfus Apher Sci. 2011;44:321-5.

Publisher's Note Springer Nature remains neutral with regard to jurisdictional claims in published maps and institutional affiliations. 